\title{
CD19 and immunophenotype of bone marrow plasma cells in monoclonal gammopathy of undetermined significance
}

\author{
M Zandecki, T Facon, F Bernardi, V Izydorczyk, L Dupond, M François, R Reade, \\ T Iaru, F Bauters, A Cosson
}

\begin{abstract}
Aims-To determine whether a particular phenotype or antigen is preferentially related to monoclonal gammopathies of undetermined significance (MGUS).

Methods-Bone marrow specimens from 56 patients with MGUS were stained immunocytochemically (ABC peroxidase) for CD38, CD56, CD9, CD10, CD19, CD20, CD22, and MB2. Specimens from patients recently diagnosed with multiple myeloma and reactive bone marrow samples were studied in parallel.

Results-CD38 was expressed on all plasma cells from all MGUS samples tested, while $36 \%$ were positive for CD56. CD9 and MB2 were both expressed strongly; CD20 was moderately expressed, and staining for CD10 and CD22 was uncommon. For these five $B$ cell antigens there was no clear difference between their expression in MGUS and in multiple myeloma. A great difference was found for CD19: in MGUS this antigen was expressed on $2-91 \%$ of plasma cells (mean $35 \%$ ) and $77 \%$ patients had $>10 \%$ positive plasma cells; in multiple myeloma its expression was low and only $12 \%$ patients had $>10 \%$ positive plasma cells. When these results were converted to numbers of CD19 postive plasma cells per 100 nucleated bone marrow cells, reactive bone marrow and MGUS specimens had a similar number of positive plasma cells. There was no correlation between expression of any of the antigens tested.
\end{abstract}

Conclusions-Many of the so-called pre$B, B$ or activation antigens are present on plasma cells from MGUS specimens, and expression of CD9, CD10, CD20, CD22, MB2, and CD38 in MGUS was very similar to that in multiple myeloma. CD56 was frequently expressed in MGUS. In this series CD19 was highly expressed in MGUS but not in multiple myeloma. Plasma cells bearing this antigen could represent the non-neoplastic process and determination of its expression could be useful for the diagnosis of MGUS.

(f Clin Pathol 1995;48:548-552)

Keywords: Monoclonal gammopathy, immunophenotype, CD19, multiple myeloma.

Over the past few years, the immunophenotype of plasma cells from patients with multiple myeloma has been studied extensively, showing that early B lineage associated antigens, such as CD10 and CD19, ${ }^{1-5}$ as well as myelomonocytic cell surface markers (CD33, CD13) ${ }^{5-7}$ are expressed on neoplastic plasma cells. These data suggested either lineage infidelity or a primary neoplastic event early in haematopoiesis. ${ }^{7-9}$ With regard to plasma cells, most information about their phenotype has resulted, as there are very few present in bone marrow and lymph nodes, from extrapolation from malignant myelomas ${ }^{310-13}$ or myeloma cell lines ${ }^{613-15}$ and rarely from in situ characterisation. ${ }^{1016}$ Using multiparameter flow cytometry, Terstappen et $a l^{17}$ recently showed that myeloid and early $\mathrm{B}$ cell markers (CD10, CD19, CD20, and CD22) are expressed within the normal plasma cell population. Harada et $a l^{18}$ using two colour flow cytometry to distinguish normal plasma cells from mature myeloma cells, found that among the various early $B$ antigens tested, CD19 was consistently expressed on normal plasma cells and not on myeloma cells, whereas CD10 and CD20 were not expressed on normal plasma cells.

Monoclonal gammopathy of undetermined significance (MGUS) is observed in up to $3 \%$ of patients aged over 70 years and in 1-1.6\% of those aged over 50 years. ${ }^{19-22}$ Some patients with MGUS will develop true multiple myeloma or amyloidosis after five to 35 years, whereas others will remain stable and finally die without evidence of multiple myeloma or a related disorder. ${ }^{22}$ MGUS is associated with a monoclonal immunoglobulin peak in serum and a slight elevation of monotypic bone marrow plasma cells. CD56 expression on plasma cells from monoclonal gammopathies has been studied extensively and its expression is high in multiple myeloma and low or absent in MGUS, ${ }^{182324}$ but may be expressed in some. ${ }^{25-27}$ By examining paraffin wax embedded bone marrow sections, Dehou et $a l^{28}$ showed that the MB2 monoclonal antibody was strongly expressed by neoplastic plasma cells, whereas expression was low or absent in plasma cells of patients with MGUS. Otherwise, information about the immunophenotype of plasma cells in MGUS is limited to small series of patients. ${ }^{1827}$

To characterise the immunophenotype of plasma cells in MGUS, bone marrow smears from 56 patients with MGUS were stained immunocytochemically for CD38, CD56 and various B cell antigens including CD9, CD10, CD19, CD20, CD22, and MB2. Smears from 
107 patients presenting with multiple myeloma were also studied for expression of the same antigens. Our aim was to determine whether a particular phenotype or antigen is preferentially related to MGUS.

\section{Methods}

Fifty six patients fulfilling criteria for MGUS ${ }^{22}$ were studied. All patients had been followed for at least one year. Monoclonal peak was as follows: IgG $\kappa$ in 23 patients, IgG $\lambda$ in 19 patients, IgA $\kappa$ in four patients, IgA $\lambda$ in seven patients, and biclonal in three patients (IgG $\kappa$ and $\lambda$ for one patient, and $\operatorname{IgG} \lambda$ and $\operatorname{IgA} \lambda$ for two patients). Patients presenting with IgM gammopathy were excluded.

The patients presenting with multiple myeloma were classified according to the Durie and Salmon staging system as follows: 39 patients had stage I, 24 had stage II, and 44 had stage III disease. All patients were studied at diagnosis, before commencement of treatment.

Eight patients with a moderate excess of bone marrow plasma cells were also studied: two patients had drug agranulocytosis, two had drug cytopenia, two had idiopathic thrombocytopenia, and two had hepatitis A. None of these eight patients had a monoclonal peak and their plasma cells were regarded as reactive.

Bone marrow smears were spread after sternal or posterior iliac crest puncture. Slides were stained with May-Grünwald-Giemsa. For determination of the per cent of bone marrow plasma cells, 1000 consecutive cells were enumerated for reactive bone marrow and MGUS, and 500 consecutive cells for multiple myeloma. Remaining slides were allowed to dry for 16-24 hours, were wrapped in aluminium foil, and stored at $-20^{\circ} \mathrm{C}$ until analysis.

The following monoclonal antibodies were used: IOB 2 (CD9) and IOB 6 (CD38) (Immunotech, Marseille, France); CD19 and CD20 (L26) (Dako, Glostrup, Denmark); B3 (CD22) (Coulter, Florida, USA), MB2 (Clonab-Biotest, Dreieich, Germany), Leu 19 (CD56) (Becton Dickinson, California, USA). IOT 5 (Immunotech) was used to detect CD10 expression in all patients; J5 (Coulter) was used in 35 patients (20 with MGUS and 15 with multiple myeloma) for comparison. All antigens could not be tested in all patients because of the limited number of bone marrow slides available.
Antigenic expression was determined using an avidin-biotin peroxidase technique (Vectastain ABC Elite, Vector Laboratories). Slides were fixed for 10 minutes in cold acetone for determination of CD19 and in acetone paraformaldehyde for all other antigens. Slides were incubated with successive layers of horse serum, the relevant monoclonal antibodies at optimal dilution (see below) and biotinylated antibodies. Endogenous peroxidase was quenched using methanol containing $0.3 \%$ perhydrol. Peroxidase conjugated avidinbiotin complex was then layered on slides and peroxidase activity revealed using diaminobenzidine and perhydrol. All slides were counterstained with diluted Giemsa. A negative control (no monoclonal antibody, or mouse IgG instead of monoclonal antibody) was included in some of the experiments. The optimal dilution for each monoclonal antibody was that used in our laboratory for the determination of the immunophenotype of acute leukaemia or peripheral blood lymphocytes with the exception of CD10. For this latter antigen, the monoclonal antibody was concentrated fourfold and blood smears from a patient with common acute lymphoid leukaemia was used as a positive control. MB2 was used at a 1 in 20 dilution. For all monoclonal antibodies tested (except CD10), the presence of positive and negative lymphocytes was required on each sample for interpretation of reactivity. At least 100 consecutive plasma cells were enumerated for reactive bone marrow and MGUS samples, and at least 200 consecutive plasma cells were enumerated for multiple myeloma samples.

Serum electrophoresis, immunoelectrophoresis and determination of the amount of each immunoglobulin class present were performed according to conventional methods.

Data analyses were performed using the $\chi^{2}$ test and the Mann-Whitney U test.

\section{Results}

For each monoclonal antibody tested, a positive reaction occurred when plasma cells stained brown. Some lymphocytes were also stained brown and were easily distinguished from plasma cells by their morphology; their reactivity was used as a positive control (table). A reaction was considered positive when at least $50 \%$ of plasma cells reacted.

CD38 was expressed on all plasma cells of all patients with either reactive bone marrow, MGUS or multiple myeloma. No unreactive

Per cent of patients in whom most plasma cells (>50\%) expressed the relevant antigen. For each antigen tested, the number of patients varied according to number of available smears

\begin{tabular}{|c|c|c|c|c|c|}
\hline & \multirow[b]{2}{*}{$\begin{array}{l}\text { Reactive bone marrow } \\
(n=4 \text { to } 7)\end{array}$} & \multirow[b]{2}{*}{$\begin{array}{l}\text { MGUS } \\
(n=20 \text { to 52) }\end{array}$} & \multicolumn{2}{|c|}{ Multiple myeloma } & \multirow[b]{2}{*}{$\begin{array}{l}\text { Difference between MGUS } \\
\text { and stage IMM ( } p \text { value) }\end{array}$} \\
\hline & & & $\begin{array}{l}\text { Stage I } \\
(n=16 \text { to } 34)\end{array}$ & $\begin{array}{l}\text { All patients } \\
(n=31 \text { to } 96)\end{array}$ & \\
\hline $\begin{array}{l}\text { CD38 } \\
\text { CD9 } \\
\text { MB2 } \\
\text { CD20 } \\
\text { CD10 } \\
\text { CD22 } \\
\text { CD56 }\end{array}$ & $\begin{array}{r}100 \% \\
100 \% \\
100 \% \\
0 \% \\
0 \% \\
0 \% \\
0 \%\end{array}$ & $\begin{array}{r}100 \% \\
80 \% \\
70 \% \\
20 \% \\
0 \% \\
3 \% \\
36 \%\end{array}$ & $\begin{array}{r}100 \% \\
75 \% \\
68 \% \\
15 \% \\
5 \% \\
6 \% \\
62 \%\end{array}$ & $\begin{array}{r}100 \% \\
70 \% \\
56 \% \\
16 \% \\
1 \% \\
16 \% \\
55 \%\end{array}$ & $\begin{array}{l}\text { NS } \\
\text { NS } \\
\text { NS } \\
\text { NS } \\
\text { NS } \\
\mathrm{p}=0.01\end{array}$ \\
\hline
\end{tabular}

$\mathrm{MM}=$ Multiple myeloma. 


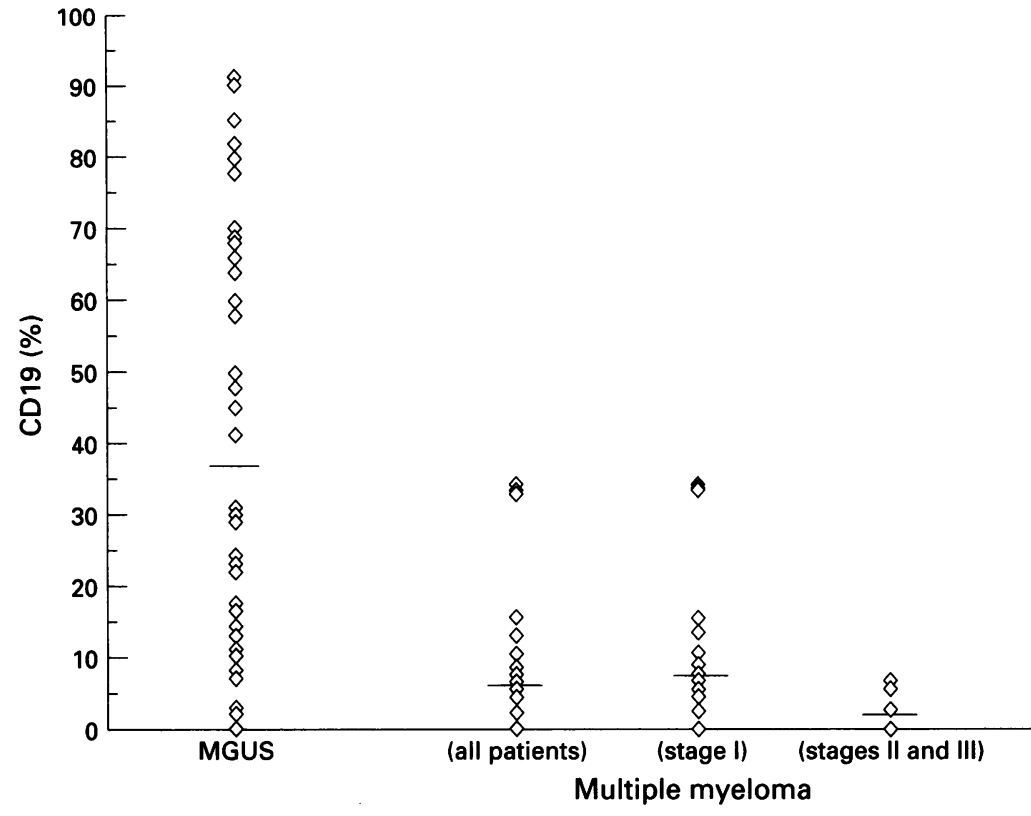

Expression of CD19 on plasma cells from patients with MGUS and multiple myeloma.

plasma cells were observed in these patients. For CD9, plasma cells were positive in all four patients with reactive bone marrow and in most patients with MGUS and multiple myeloma. Plasma cells were also positive for MB2 in all four patients with reactive bone marrow, and $70 \%$ of patients with MGUS. Of the patients with multiple myeloma, $68 \%$ of those with stage I and $56 \%$ overall (that is, all stages) expressed MB2. Plasma cells of $20 \%, 16 \%$ and $15 \%$ of patients with MGUS, multiple myeloma (all stages) and stage I multiple myeloma, respectively, were positive for CD20. Expression of CD20 was low on reactive bone marrow samples, and only a few (1-25\%) plasma cells stained positively. Both monoclonal antibodies used to determine CD10 expression (J5 and IOT 5) gave the same reactivity pattern (data not shown). Only one in 71 patients with multiple myeloma was positive for CD10; this patient had stage I disease. Plasma cells from reactive bone marrow and MGUS samples were negative for CD10 expression although a few plasma cells (2-6\%) stained positively in six patients. Plasma cells from samples of reactive bone marrow were negative for CD22, while only one in 30 patients with MGUS was positive for this antigen. Five of $31(16 \%)$ patients with multiple myeloma were positive for expression of CD22; one of these patients had stage I disease, and the other four had stages II or III disease. CD22 was expressed more frequently in stages II and III multiple myeloma, but the number of patients tested was too low to allow definite conclusions to be drawn. Some plasma cells (3 to $28 \%$ ) expressed CD56 in six of seven patients with reactive bone marrow. CD56 ( $>50 \%$ plasma cells positive) was highly expressed in $36 \%$ of patients with MGUS, in $55 \%$ of patients with multiple myeloma, and in $62 \%$ when only patients with stage I disease were considered $(p=0.01)$. Most patients with multiple myeloma had either minimal $(<10 \%)$ or extensive ( $>50 \%$ ) staining, whereas intermediate reactivity (11-50\%) occurred more frequently (data not shown) in those with MGUS.

In seven of eight patients with reactive bone marrow 62 to $96 \%$ of their plasma cells expressed CD19. Only one patient with viral hepatitis did not express this antigen. Expression of CD19 in patients with MGUS varied (figure): plasma cells were unstained in one patient and in all other patients reactivity ranged from 2 to $91 \%$ (mean $38 \%$ ); in 37 of $48(77 \%)$ patients over $10 \%$ of plasma cells were CD19 positive. Expression of CD19 in MGUS seemed to have a continuous spectrum. Overall expression of CD19 was low in patients with multiple myeloma: less than $10 \%$ of plasma cells stained in 45 of 51 patients. CD19 was not highly expressed in any of the patients with multiple myeloma and moderate staining (14-34\%) was found in only six patients who all had stage I disease. A highly statistically significant difference $(p=0.0001)$ was found for expression of CD19 on plasma cells of patients with MGUS and multiple myeloma (overall, or in those with stage I disease only) (figure).

The per cent of bone marrow plasma cells was 0.9 to $3.0 \%$ in reactive bone marrow, 0.9 to $6.2 \%$ in MGUS, and 4 to $95 \%$ in multiple myeloma. The actual number of CD19 positive plasma cells in bone marrow of individual patients ( $\%$ bone marrow plasma cells multiplied by \% CD19 positive plasma cells) showed that the upper limit was $2.9 \%$ for reactive bone marrow, $4.5 \%$ for MGUS and $7 \cdot 8 \%$ for multiple myeloma. However, in 45 of 48 patients with MGUS the actual number of CD19 positive plasma cells was within the same range as for reactive bone marrow; for multiple myeloma, the actual number was lower than that found in either reactive bone marrow or MGUS samples. Therefore, an actual excess of CD19 positive plasma cells was an infrequent finding in monoclonal gammopathies.

We failed to find any correlation between the expression of any of the antigens tested. For CD19 and CD56, however, although no statistical correlation between high expression of one antigen and low expression of another was found, three groups could be identified: high CD19 (>50\%) and low CD56 (<30\%) expression; high CD56 and low CD19 expression; and low expression of both antigens. Interestingly, with the exception of one patient, we failed to find a subgroup of patients with high expression of both CD19 and CD56.

In MGUS samples, the concentration of IgG was 9.0 to $35.9 \mathrm{~g} / 1$ (normal range $8-18 \mathrm{~g} / \mathrm{l}$ ) for patients with an IgG peak and that of IgA was 3.0 to $12.2 \mathrm{~g} / 1$ (normal range $0.9-4.5 \mathrm{~g} / \mathrm{l}$ ) for patients with an IgA peak. In seven patients the non-involved immunoglobulin (IgM, IgG or $\operatorname{IgA}$ ) concentration was reduced. There was no correlation between expression of CD19 on plasma cells and either the nature (IgG or IgA, $\kappa$ or $\lambda$ light chains), the peak immunoglobulin concentration, or the reduction in non-involved immunoglobulin concentrations. 


\section{Discussion}

We used immunocytochemistry to determine the phenotype of plasma cells of patients with MGUS. CD10 and CD22 were expressed at low levels whereas positive staining occurred frequently for CD9, MB2 and CD20. While expression of CD19 and CD56 was not restricted solely to either MGUS or multiple myeloma, there was a statistically significant difference in the staining pattern.

CD10 may be found on some normal plasma cells, ${ }^{17}$ but these data have not been confirmed $^{18}$; conflicting results were also encountered in multiple myeloma. ${ }^{13182729-31}$ In two small series ${ }^{1827}$ CD10 was not expressed in MGUS, and our results confirm these data. CD9 is commonly expressed on plasma cells of patients with multiple myeloma, ${ }^{535}$ and in our series extensive expression was found in those with multiple myeloma, MGUS and reactive bone marrow. CD10 and CD9 may be related to the pre $B$ nature of plasma cells and also to $B$ cell activation ${ }^{32-34}$ : in MGUS expression was low for CD10 and high for CD9, suggesting that the mechanisms triggering their presence could differ.

Low or no expression of CD22 seems to be a common finding on plasma cells in multiple myeloma, ${ }^{14}$ myeloma cell lines, ${ }^{14}$ normal plasma cells, ${ }^{17}$ or MGUS (our series). CD20 may ${ }^{17}$ or may not ${ }^{18}$ be found on some normal plasma cells, and a subset of patients with multiple myeloma express this pan-B antigen. ${ }^{5142735}$ In our series expression of CD20 was not an infrequent finding, and its distribution was comparable on plasma cells from patients with either MGUS or multiple myeloma. Although expression varied slightly when expressed as per cent positive cells, there was no difference in the expression of CD10, CD9, CD22, or CD20 in reactive bone marrow, MGUS and multiple myeloma samples.

Paraffin wax embedded bone marrow sections show strong cytoplasmic positivity to MB2 in most multiple myeloma cases, ${ }^{36}$ whereas plasma cells from patients with MGUS show either weak or no reactivity. ${ }^{28}$ Bone marrow smears are widely used in the diagnosis of MGUS, and we tested this monoclonal antibody on bone marrow slides. We observed strong reactivity in $70 \%$ of patients with MGUS and comparable results (56\%) were found for patients with multiple myeloma. So, when this monoclonal antibody is used on bone marrow sections, its ability to discriminate between MGUS and multiple myeloma disappears.

CD56 (N-CAM) is an adhesion molecule expressed on most plasma cells in 62 to $82 \%$ of patients with multiple myeloma ${ }^{91823-25}$ but is absent or expressed at a low level on normal and reactive plasma cells. ${ }^{1825-27}$ In MGUS, CD56 is expressed weakly or not at all on plasma cells. ${ }^{23} 24$ Other reports, ${ }^{25-27}$ however, showed that some plasma cells from patients with MGUS could express this antigen $(36.5 \%$ in our series). Although this percentage was high, there was a clear statistical difference with stage I multiple myeloma.

CD19 is present in almost all stages of B cell ontogeny ${ }^{37}$ and is not highly expressed in multiple myeloma. ${ }^{3142735}$ In MGUS, using flow cytometry, Leo et $a l^{27}$ failed to find any reactivity in the eight patients tested, whereas Harada $e t$ $a l^{18}$ found variable positivity in all five patients tested. Using immunocytochemistry, we also found that a variable but important percentage of plasma cells expressed CD19, and the difference in expression between MGUS and multiple myeloma was highly significant. Therefore it may be possible to use CD19 expression to discriminate between MGUS and stage I multiple myeloma. However, it is important to note that, when CD19 positive plasma cells were expressed as a percentage of all nucleated bone marrow cells and compared with the value obtained for reactive bone marrow, no real excess of CD19 positive plasma cells was found in most MGUS samples; in multiple myeloma these numbers were also low and, in most cases, were even lower than those found in MGUS. In multiple myeloma the few CD19 positive plasma cells may be residual non-neoplastic cells and aberrant expression may be restricted to a few patients. One might hypothesise that in MGUS CD19 positive plasma cells could also be related to the nonneoplastic process. Our data confirm those of Harada et $a l^{18}$ that plasma cells do not coexpress CD19 and CD56. However, it is not yet clear whether patients with MGUS who express CD56 are more likely to develop true multiple myeloma than those who do not express this antigen.

In conclusion, we have shown that no specific immunophenotypic profile was associated with plasma cells in MGUS. CD38 was the unique antigen consistently expressed on all plasma cells from patients with MGUS. The various B cell antigens studied were expressed with comparable frequency in MGUS, multiple myeloma, and reactive bone marrow, with the exception of CD19. This latter antigen was rarely expressed in multiple myeloma, whereas most or many normal and MGUS plasma cells were positive. Do CD19 positive plasma cells represent the non-neoplastic mass? Will these plasma cells disappear or gradually lose this antigen in patients developing true multiple myeloma? Whatever the explanation concerning the presence of CD19 on plasma cells, as it is highly expressed in MGUS and not in multiple myeloma, determination of the expression of this antigen may be used, along with determination of the proliferative activity, ${ }^{38}$ CD56 expression ${ }^{1823-27}$ and multidrug resistance, ${ }^{24}$ to discriminate between these two conditions.

We thank Roselyne Coudenis, Corrine Fougère and Danièle Talandier for their expert technical assistance.

This study was supported by Grants from Comite du Nord de la Ligue de Recherche contre le Cancer and Centre Hospitalier Régional et Universitaire de Lille.

1 Durie BGM, Grogan TM. Calla-positive myeloma: an ag gressive subtype with poor survival. Blood 1985;66:229-32. 2 Tazzari PL, Gobbi M, Dinota A, Bontadini A, Grassi G Cerato $\mathrm{C}$, et al. Normal and neoplastic plasma cell membrane phenotype: studies with new monoclonal antibodies. Clin Exp Immunol 1987;70:192-200.

3 Epstein J, Barlogie B, Katzmann J, Alexanian R. Phenotypic heterogeneity in aneuploid multiple myeloma indicates pre-B cell involvement. Blood 1988;71:861-5.

4 King MA, Nelson DS. Tumor cell heterogeneity in multiple 
myeloma: antigenic, morphologic, and functional studies of cells from blood and bone marrow. Blood 1989;73: 1925-35.

5 San Miguel JF, Gonzalez MM, Gascon A, Moro MJ, Hernandez JM, Ortega $\mathrm{F}$, et al. Immunophenotypic heterogeneity of multiple myeloma: influence on the biology and clinical course of the disease. Br $\mathcal{F}$ Haematol 1991;71: 185-90.

6 Grogan TM, Durie BGM, Spier CM, Richter L, Vela E. Myelomonocytic antigen-positive multiple myeloma. Blood 1989;73:763-9.

7 Epstein J, Xiao H, He HY. Markers of multiple hematopoietic-cell lineages in multiple myeloma. $N$ Engl $f$ Med 1990;322:664-8.

8 Barlogie B, Epstein J, Selvanayagam P, Alexanian R. Plasma cell myeloma. New biological insights and advances in cell myeloma. New biological ins

therapy. Blood 1989;73:865-79.
9 Drach J, Gattringer C, Huber H. Expression of the neural adhesion molecule (CD56) by human myeloma cells. Clin Exp Immunol 1991;83:418-22.

10 Nathan PD, Walker L, Hardie D, Richardson P, Khan M Johnson GD, et al. An antigenic study of human plasma cells in normal tissue and in myeloma: identification of a novel plasma cell associated antigen. Clin Exp Immunol 1986;65:112-18.

11 San Miguel JF, Caballero MD, Gonzalez M, Zola H, Lopez Borrasca A. Immunological phenotype of neoplasms in volving the B cell in the last step of differentiation. $\mathrm{Br} \mathcal{F}$ volving the B cell in the
Haematol 1986;62:75-83.

12 Joshua DE, Ioannidis R, Brown R, Francis SE, Gibson J, Kronenberg $H$. Multiple myeloma: relationship between light chain isotype suppression, labelling index of plasma cells, and CD38 expression peripheral blood lymphocytes. Am ₹ Hematol 1988;29:5-11.

13 Duperray C, Klein B, Durie BGM, Zhang H, Jourdan M, Poncelet $\mathrm{B}$, et al. Phenotypic analysis of human myeloma cell lines. Blood 1989;73:566-72.

14 Hamilton MS, Ball J, Bromidge E, Franklin IM. Surface antigen expression of human neoplastic plasma cells includes molecules associated with lymphocyte recirculation and adhesion. Br $\mathcal{f}$ Haematol 1991;78:60-5.

15 Weinreich SS, Vom dem Borne AEGK, Van Lier RAW, Feltkamp CA, Slater RM, Wester MR, et al. Characterization of a human plasmocytoma line. Br $f$ Haematol 1991;79:226-34.

16 Mayumi M, Kuritani T, Kubagawa H, Cooper MD. IgG subclass expression by human $B$ lymphocytes and plasma cells: B lymphocytes precommitted to IgG subclass can be preferentially induced by polyclonal mitogens with $T$ cell help. F Immunol 1983;130:671-7.

17 Terstappen LWMM, Johnsen S, Segers-Nolter IMJ, Loken $M R$. Identification and characterization of plasma cells in normal human bone marrow by high-resolution flow in normal human bone marrow by
cytometry. Blood 1990;76:1739-47.

18 Harada H, Kawano MM, Huang N, Harada Y, Iwato K, Tanabe $\mathrm{O}$, et al. Phenotypic difference of normal plasma cells from mature myeloma cells. Blood 1993;81:2658-63.

19 Hällen J. Frequency of "abnormal" serum globulins (Mcomponents) in the aged. Acta Med Scand 1963;173. 737-44.

20 Kyle RA, Finkelstein S, Elveback LR, Kurtland LT. Incidence of monoclonal proteins in a Minnesota community with a cluster of multiple myeloma. Blood 1972;40:718-24

21 Saleun JP, Vicariot M, Deroff P, Morin JF. Monoclonal gammopathies in the adult population of Finistère, France. gammopathies in the adult pop $1982 ; 35: 63-8$.
22 Kyle RA. "Benign" monoclonal gammopathy-After 20 to 35 years of follow-up. Mayo Clin Proc 1993;68:26-36.

23 Van Camp B, Durie BGM, Spier C, De Waele M, Van Riet

I, Vala E, et al. Plasma cells in multiple myeloma express a natural killer cell-associated antigen: CD56 (NKH-1; Leu-19). Blood 1990;76:377-82.

24 Sonneveld P, Durie BGM, Lokhorst HM, Frutiger Y, Schoester M, Vela EE. Analysis of multidrug-resistance (MDR1) glycoprotein and CD56 expression to separate monoclonal gammopathy from multiple myeloma. Brf Haematol 1993;83:63-7.

25 Van Riet I, De Waele M, Remels L, Lacor P, Schots R, Van Camp B. Expression of cytoadhesion molecules (CD56, CD54, CD18 and CD29) by myeloma plasma cells. $B r f$ Haematol 1991;79:421-7.

26 Barker HF, Hamilton MS, Ball J, Drew M, Franklin IM. Expression of adhesion molecules LFA-3 and N-CAM on normal and malignant human plasma cells. $B r \mathcal{F}$ Haematol 1992;81:331-5.

27 L eo R, Boeker M, Peest D, Hein R, Bartl R, Gessner JE, et al. Multiparameter analyses of normal and malignant human plasma cells: $\mathrm{CD} 38++, \mathrm{CD} 56+, \mathrm{CD} 54+, \mathrm{cIg}+$ is the common phenotype of myeloma cells. Ann Hematol 1992;64:132-9.

28 Dehou MF, Schots R, Lacor P, Arras N, Verhavert $P$, Klöppel G, et al. Diagnostic and prognostic value of the
$\mathrm{MB2}$ monoclonal antibody in paraffin-embedded bone marrow sections of patients with multiple myeloma and marrow sections of patients with multiple myeloma and monoclonal gammopathy of unde

29 Chan CSP, Wormsley SB, Pierce LE, Peter JB, Schechter GP. B-cell surface phenotypes of proliferating myeloma cells: target antigens for immunotherapy. Am $\mathcal{F}$ Hematol 1990;33:101-9.

30 Grogan TM, Durie BGM, Lomen C, Spier C, Wirt DP, Nagle $R$, et al. Delineation of a novel pre-B cell component in plasma cell myeloma: immunochemical, immunophenotypic, genotypic, cytologic, cell culture and kinetic phenotypic, genotypic, cytologic,
features. Blood 1987;70:932-42.

31 Omedé P, Boccadoro M, Fusaro A, Gallone G, Pileri A Multiple myeloma: “early" plasma cell phenotype identifies patients with aggressive biological and clinical characteristics. Br $\mathcal{F}$ Haematol 1993;85:504-13.

32 Kiyokawa N, Kokai Y, Ishimoto $K$. Characterization of the CALLA (CD10) as an activation molecule on mature human B cells. Clin Exp Immunol 1990;79:322-7.

33 Zola $\mathrm{H}$. The surface antigens of human $B$ lymphocytes. Immunol Today 1987;8:308-15.

34 Zeleznik-Le NJ, Metzgar RS. Expression of CD9 antigen on normal activated human B cells. Cell Immunol 1989; 123:70-82.

35 Shimazaki C, Fried J, Perez AG, Scheinberg DA, Atzpodien $\mathrm{J}$, Wang CY, et al. Immunophenotypic analysis of lymphocytes and myeloma cells in patients with multiple myeloma. Acta Haematol 1990;83:123-9.

36 Hall PA, D'Ardenne AJ, Butler MG, Habeshaw JR, Stansfeld AG. New marker of B lymphocytes, MB2: comparison with other lymphocyte subset markers active in conventionally processed tissue sections. $\mathcal{F}$ Clin Pathol 1987; 40:151-6.

37 Uckun FM. Regulation of human B cell ontogeny. Blood 1990;76:1908-23.

38 Greipp PR, Witzig TE, Gonchoroff NJ, Habermann TM Katzmann JA, O'Fallon WM, et al. Immunofluorescence labeling indices in myeloma and related monoclonal gammopathies. Mayo Clin Proc 1987;62:969-77. 